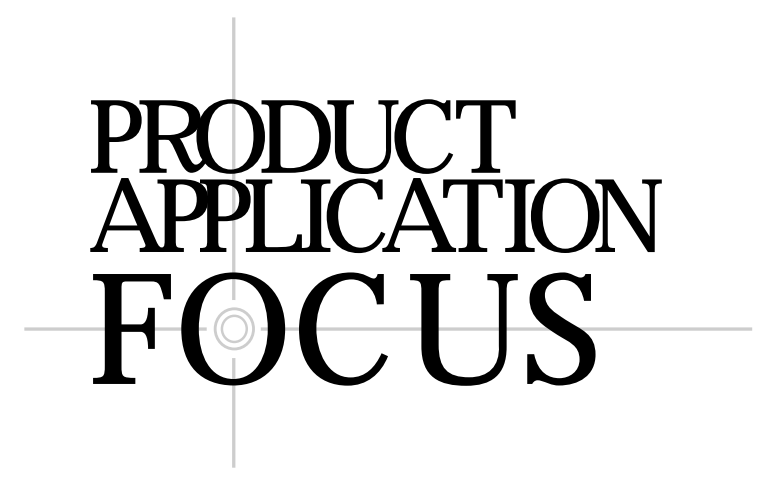

\title{
Isolation of Genomic DNA from Blood Using a Novel Filter-Based DNA Purification Technology
}

\author{
M.P. Baker, A. Mitchell, C. Bridge, S. Martin, F. Holder, N.D. Pathirana, A. Jarvis, \\ and $\mathrm{N}$. Butt \\ Whatman BioScience, Cambridge, UK
}

BioTechniques 31:142-145 (July 2001)

\begin{abstract}
A novel DNA purification technology is described that enables the purification of pure dsDNA from blood. When compared to existing DNA purification methods, the Whatman BioScience Purification System (WBPS) offers a fast and convenient way to recover high yields of DNA. WBPS is based on a unique filter system that entraps DNA within a matrix. This allows the process to be performed in a single unidirectional reaction vessel, reducing user interaction and multiple centrifugation steps.
\end{abstract}

\section{INTRODUCTION}

One of the prerequisites of many molecular biological procedures is the extraction of pure nucleic acid. Both DNA and RNA can be purified using a variety of different techniques from a broad range of material. When purifying DNA from blood samples, it is important to avoid heme contamination, as this may have an inhibitory effect on downstream PCR (1). Therefore, in most current protocols, extraction of DNA from blood requires the removal of red blood cells by osmotic shock. DNA can then be purified from the remaining sample, which is enriched for nucleated white blood cells. Nucleated cells are usually lysed in a detergent buffer, allowing the DNA to be released in soluble form. This can be further purified using organic solvents $(5,7)$, binding to surfaces using ionic interactions $(2,3,8)$, or using a high salt environment $(4,6)$. In the most widely employed methods (salting out and chloroform), a further DNA precipitation stage is necessary to remove salt residue.

We report here the Whatman BioScience Purification Sys- tem (WPBS), a novel extraction procedure that does not require a binding stage, a final precipitation, or the use of hazardous chemicals. In this novel procedure, dsDNA can be eluted directly from a column into a collection vessel and can be processed immediately. Furthermore, since DNA is eluted in pure soluble form, there is no requirement for a precipitation stage, allowing the immediate and reliable quantitation of DNA. This process has been shown to work for blood $(50-\mu \mathrm{L}$ to $10-\mathrm{mL}$ volumes) but should be capable of removing DNA from any large nucleated cell. The material purified is of restriction digest and PCR processing quality that enables the amplification of both large fragments and rare DNA sequences. The format of this process not only lends itself to fast and efficient DNA recovery but also for high-throughput automation.

\section{MATERIALS AND METHODS}

Genomic DNA was purified from $10 \mathrm{~mL}$ whole blood (obtained from East of England Blood Transfusion Service) using WBPS (outlined in Figure 1), a silica-based extraction kit, chloroform extraction kit, and two salting out kits (all according to the manufacturers' instructions). DNA was collected in $2-\mathrm{mL}$ tubes and normalized to a final volume of $1.5 \mathrm{~mL}$. DNA pellets were resuspended for $20 \mathrm{~h}$ at $4^{\circ} \mathrm{C}$ when performing extractions that required an ethanol precipitation step.

\section{Summary of the WBPS Protocol}

The WBPS protocol allows the simultaneous purification of DNA from up to eight blood samples. This is achieved using a vacuum manifold that has a capacity for eight isolation 
vessels. The purification process involves placing whole blood into an isolation vessel followed by the addition of 10 $\mathrm{mL}$ solution 1 (hypotonic salt solution), which reduces the viscosity of the blood and aids red blood cell lysis. The mixture of blood and solution 1 is filtered using a vacuum enabling the capture of white blood cells within a glass fiber filter matrix. An additional $20-\mathrm{mL}$ volume of solution 1 is added and filtered under vacuum to remove membranous debris from the glass fiber filter. Lysis of white blood cells captured within the filter matrix is facilitated by the addition of $10 \mathrm{~mL}$ solution 2 (SDS solution). At this stage, DNA is released and becomes entrapped physically around the fibers of the filter matrix. Residual solution 2 and contaminating cell debris are removed by adding $10 \mathrm{~mL}$ solution 3 (salt solution), which is filtered using a vacuum. DNA is released from the glass fiber filter matrix by incubating the isolation vessels at $90^{\circ} \mathrm{C}$ for $15 \mathrm{~min}$ using a specialized heating station. Pure DNA is then eluted from the isolation vessel (using a clean manifold) in $1.5 \mathrm{~mL}$ solution 4 (10 mM Tris, $\mathrm{pH} \mathrm{8.0,} \mathrm{and} 1$ mM EDTA) using a vacuum.

\section{Assays for DNA Yield and Purity}

ss and dsDNA was quantified using OliGreen ${ }^{\circledR}$ and PicoGreen ${ }^{\circledR}$ (Molecular Probes, Eugene, OR, USA) assays, respectively. For both assays, analysis was performed using a Labsystems Fluoroscan II ${ }^{\mathrm{TM}}$ (ThermoQuest, Basingstoke, UK). Before OliGreen analysis, DNA was heat denatured by incubating samples at $96^{\circ} \mathrm{C}$ for $2 \mathrm{~min}$. For both OliGreen and PicoGreen assays, DNA was diluted 1/200 in TE and incubated at $4{ }^{\circ} \mathrm{C}$ for $12 \mathrm{~h}$ to allow the samples to mix before processing as recommended by the manufacturers. The purity of DNA was determined by observing optical densities at 260/280 nm using a UV spectrophotometer (Perkin-Elmer Lambda 20; Applied Biosystems, Foster City, CA, USA).

\section{Enzyme Digests}

Mungbean nuclease (Life Technologies, Rockville, MD, USA) digests were performed on $2.7 \mu \mathrm{g}$ purified DNA that was incubated at $30^{\circ} \mathrm{C}$ for $1 \mathrm{~h}$ with $2 \mathrm{U}$ enzyme. Samples

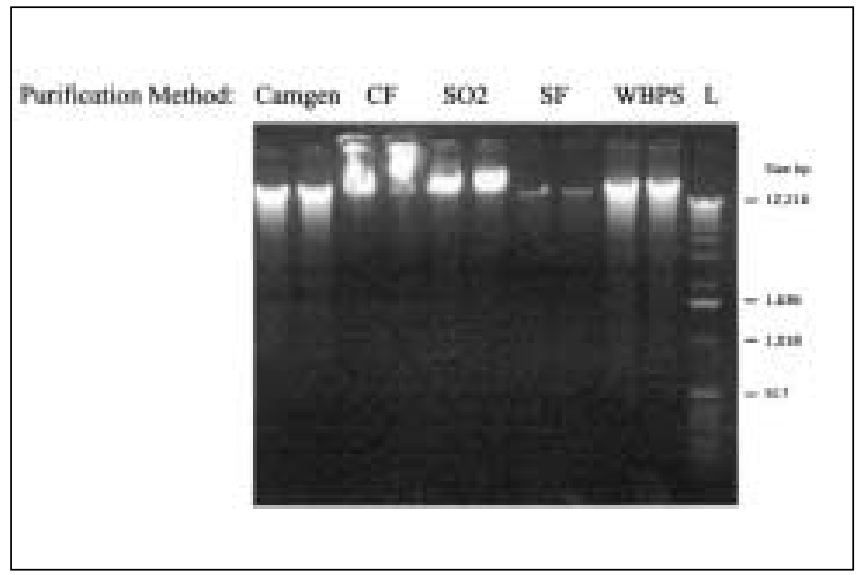

Figure 1. Duplicate DNA extractions were performed from $10 \mathrm{~mL}$ whole blood using different extraction methods. Ten microliters of each sample (normalized to the same final volume) were loaded on to a $0.8 \%$ agarose gel containing ethidium bromide. Descriptions for the abbreviations identifying each DNA purification method are shown in Table 1. Molecular weights were compared against a 1-kb DNA ladder (L) (Life Technologies). were visualized on $0.8 \%$ agarose gel. Restriction endonuclease digests were also performed on $5 \mu \mathrm{g}$ DNA using Hinf1 (Life Technologies). DNA samples were incubated at $37^{\circ} \mathrm{C}$ for $3 \mathrm{~h}$ with $1 \mathrm{U}$ restriction endonuclease.

\section{Short Tandem Repeats (STR) Analysis and PCR Assays}

Extended PCR was performed on DNA purified using the WBPS and the Camgen salting out kit (Whatman BioScience, Cambridge, UK). A 7.5-kb product was amplified from the single locus $\beta$-globin gene using Elongase ${ }^{\circledR}$ amplification kit (Life Technologies) and $50 \mathrm{ng}$ template DNA. Multilocus analysis was performed by amplification of a 670-bp product from the actin gene. Multiplex STR analysis was performed using Amp FeSTR SGM Plus ${ }^{\mathrm{TM}}$ (Applied Biosystems) and run on an ABI PRISM ${ }^{\circledR} 377$ using Long Ranger Singels ${ }^{\circledR}$ (BMA, Rockland, ME, USA) for the electrophoretic media.

\section{Determining Size of Purified Genomic DNA}

Field inversion gel electrophoresis (FIGE) was performed using $5 \mu \mathrm{g}$ DNA on a FIGE Mapper System (Bio-Rad Laboratories, Hercules, CA, USA). Samples were run on $1 \%$ pulse field grade agarose gel containing $0.5 \times \mathrm{TBE}$ at room temperature for $14 \mathrm{~h}$. The switch time ramp was between 1.5 and $3.5 \mathrm{~s}$ (linear shape) with forward and reverse voltages of 180 and $120 \mathrm{~V}$, respectively. The DNA molecular weight size standard consisted of a $\lambda$ concatamer ladder (Bio-Rad Laboratories).

\section{RESULTS AND DISCUSSION}

The WBPS offers a quick and easy alternative for purifying DNA from blood. By comparing processing times

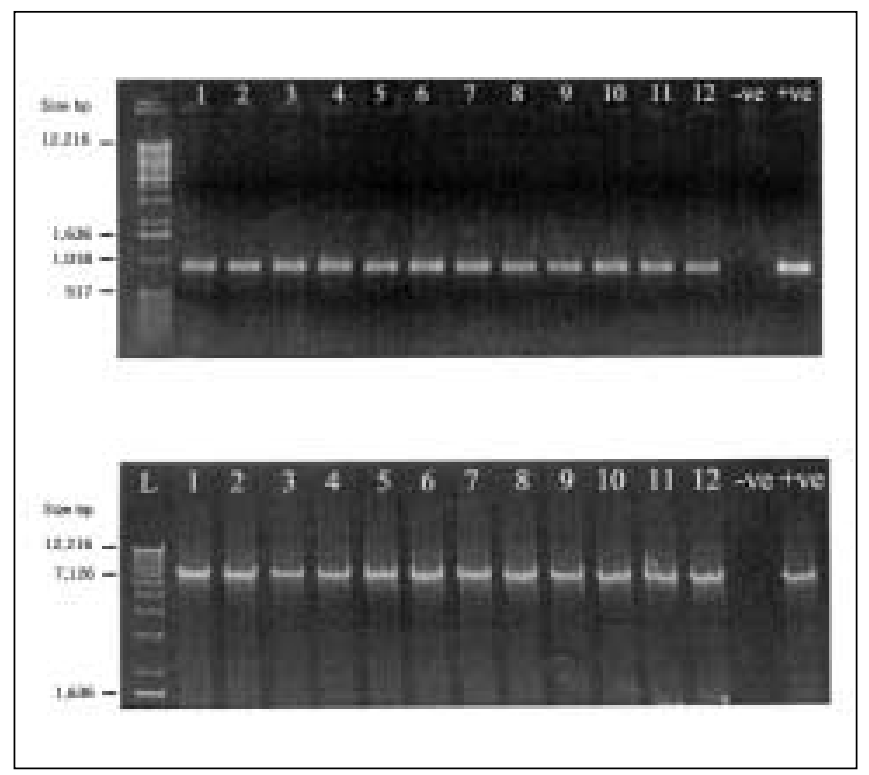

Figure 2. Amplification of different-sized fragments using template DNA purified from blood using different methods. Top panel, a 670-bp actin fragment was amplified from $20 \mathrm{ng}$ DNA purified from six $0.5-\mathrm{mL}$ clinical blood samples using WBPS (lanes 1-6) or Camgen (lanes 7-12) methods. Bottom panel, a 7.5-kb $\beta$-globin fragment was PCR amplified from $50 \mathrm{ng}$ DNA purified from twelve 10-mL clinical blood samples using WBPS. For both actin and 7.5 -kb $\beta$-globin PCR, $10 \mu \mathrm{L}$ product were separated on a $0.8 \%$ agarose gel. Molecular weights were compared against a 1-kb DNA ladder (L). 
Table 1. Duplicate DNA Extractions Were Performed from $10 \mathrm{~mL}$ Whole Blood Using Different Methods

\begin{tabular}{|c|c|c|c|c|c|c|}
\hline \multirow[b]{2}{*}{ Abbreviation } & \multirow[b]{2}{*}{ Method } & \multirow[b]{2}{*}{ Process Time } & \multicolumn{2}{|c|}{$260 / 280 \mathrm{~nm}$} & \multicolumn{2}{|c|}{ Yield $(\mu \mathrm{g})$} \\
\hline & & & 1 & 2 & 1 & 2 \\
\hline Camgen & Salting out & $96 \min ^{a}$ & 1.88 & 1.87 & 307 & 237 \\
\hline $\mathrm{SO} 2$ & Salting out & $134 \min ^{a}$ & 1.89 & 1.89 & 318 & 283.5 \\
\hline CF & Chloroform & $117 \min ^{\mathrm{a}}$ & 1.58 & 1.53 & 267 & 156 \\
\hline SF & Silica filter & $72 \min$ & 1.85 & 2.15 & 31.5 & 15 \\
\hline WBPS & Novel system & $30 \mathrm{~min}$ & 1.79 & 1.81 & 264 & 244.5 \\
\hline
\end{tabular}

between various methods of purifying DNA from blood, the WBPS system produces soluble DNA in the least amount of time (Table 1). Volumes (10 mL) of whole blood were processed using WBPS, silica-based extraction kit, chloroform extraction kit, or two Camgen salting out kits. Analysis of DNA samples on $0.8 \%$ agarose gel showed that all extraction procedures produce high molecular weight DNA (Figure 1). More detailed quantitation of DNA using the PicoGreen assay showed that the WBPS produces yields of dsDNA equivalent to or higher than those observed in the salting out, chloroform, and the silica-based extraction methods (Table 1). Furthermore, analysis of the same DNA by UV spectrophotometry shows an $\mathrm{A}_{260 / 280}$ ratio of 1.8 , indicating that

(a)

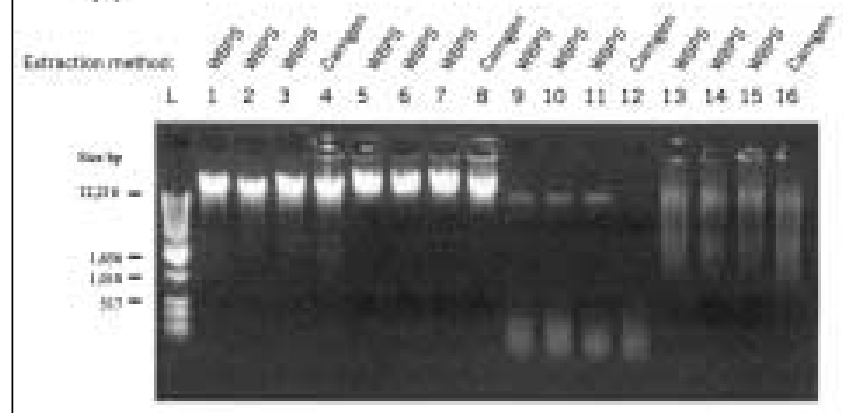

(b)

\begin{tabular}{|c|c|c|}
\hline \multirow{2}{*}{$\begin{array}{l}\text { Fetraction } \\
\text { Method }\end{array}$} & \multicolumn{2}{|c|}{ Concentration $(\mathrm{ng} / \mathrm{l}$ ) } \\
\hline & - Mungbeam & + Mungbean \\
\hline WEPS & 102.72 & 10850 \\
\hline wers & H1. an & 11035 \\
\hline hefs & $1123 \mathrm{n}$ & 113.53 \\
\hline Camban & 102.23 & ve.5g \\
\hline
\end{tabular}

Figure 3. DNA was purified from either three 10-mL blood samples using WBPS or one 10-mL blood sample using the Camgen method. (a) Purified DNA samples from both WBPS and Camgen methods were treated with $2 \mathrm{U}$ Mungbean nuclease for $1 \mathrm{~h}$ at $30^{\circ} \mathrm{C}$ (lanes 1-4). As a control for each sample, a comparison of heat-denatured DNA incubated in either the presence (lanes 9-12) or absence (lanes 13-16) of Mungbean nuclease was performed. Undigested samples were also included (lanes 5-8) to compare against Mungbeandigested DNA for both WBPS and Camgen methods. Twenty microliters of each sample under the various conditions were run on a $0.8 \%$ agarose gel. Molecular weights were compared against a 1-kb DNA ladder (L). (b) OliGreen assay was performed to determine the total amount of ss and dsDNA after incubation in the presence or absence of Mungbean nuclease. nucleic acid extracted from blood using WBPS is free from protein and salt contamination (Table 1).

An investigation into the functionality of DNA purified from WBPS compared to a salting out kit (Camgen method) was performed using different PCR conditions. DNA purified from both WBPS and the Camgen method allowed the amplification of small products from multilocus genes. In Figure 2, top panel, a 670-bp product was amplified to give equivalent band intensities using $20 \mathrm{ng}$ template DNA from both extraction procedures. DNA from 12 different blood samples was extracted using WBPS and $50 \mathrm{ng}$ of template DNA was used to amplify a 7.5-kb fragment of the single locus human $\beta$-globin gene (Figure 2, bottom panel). The results show that the WBPS can consistently produce pure DNA of a quality sufficient for long-range PCR.

Analysis of DNA by PicoGreen assay showed high yields of dsDNA when purified from blood using the WBPS. To confirm these findings, the same DNA was subjected to digestion using Mungbean nuclease that digests ssDNA, leaving regions of duplex DNA intact (Figure 3a). The results show that DNA purified using WBPS is not digested by Mungbean nuclease when compared to control DNA incubated in the absence of enzyme. DNA incubated in the presence or absence of Mungbean nuclease was subjected to analysis by OliGreen assay that quantifies both ss and dsDNA (Figure 3b). The re-

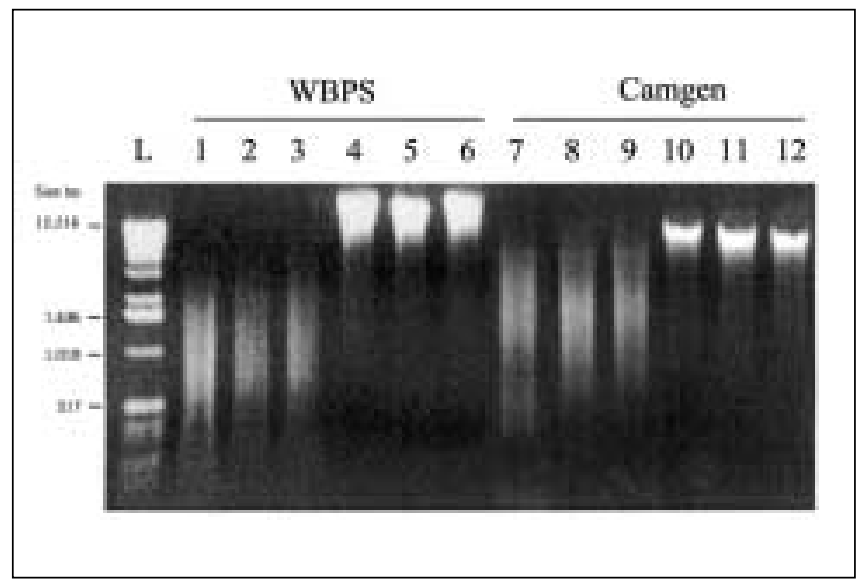

Figure 4. Restriction digest comparison. Five micrograms of DNA purified from three 10-mL blood samples using WBPS (lanes 1-3) and Camgen (lanes 7-9) methods were treated with $1 \mathrm{U}$ Hinf 1 for $3 \mathrm{~h}$ at $37^{\circ} \mathrm{C}$. Undigested DNA was included for comparison for both WBPS (lanes 4-6) and Camgen methods (lanes 10-12). Twenty microliters of each digest was separated on a $0.8 \%$ agarose gel. Molecular weights were compared against a 1-kb DNA ladder (L). 
sults show that the amount of total DNA purified using both WBPS and Camgen methods is not reduced after digestion with Mungbean nuclease, suggesting that the majority of DNA recovered using both methods is double stranded.

A restriction endonuclease was used to digest DNA purified from the WBPS and Camgen methods (Figure 4). Hinf1 recognizes a four-base cleavage site that can be observed as a band shift on a $0.8 \%$ agarose gel when digesting genomic DNA. The band shift was observed when material was digested from three separate DNA extractions performed using either WBPS or the Camgen method. In both instances, control DNA incubated in the absence of enzyme did not appear to degrade.

DNA purified using WBPS and the Camgen method was subjected to FIGE (Figure 5). This enabled a detailed analysis of genomic DNA fragment size. For both purification methods, it appeared that genomic DNA fragment sizes were spread over a broad high molecular weight range, although most fragments were in excess of $1 \mathrm{mb}$ in size. It is clear from these data that genomic DNA of this size could be used for any molecular biological application.

\section{CONCLUSION}

WBPS is a procedure completed in six easy steps and, based on recent studies, when compared to cell counts can yield recoveries of up to $90 \%$. Indeed, when compared to existing extraction procedures, DNA purified using WBPS gives equivalent or higher yields. It should be noted, however, that DNA was purified using other manufacturers' kits according to instructions, and given the complexity of existing extraction technologies, a certain amount of optimization can in some circumstances result in greater yields. In addition to

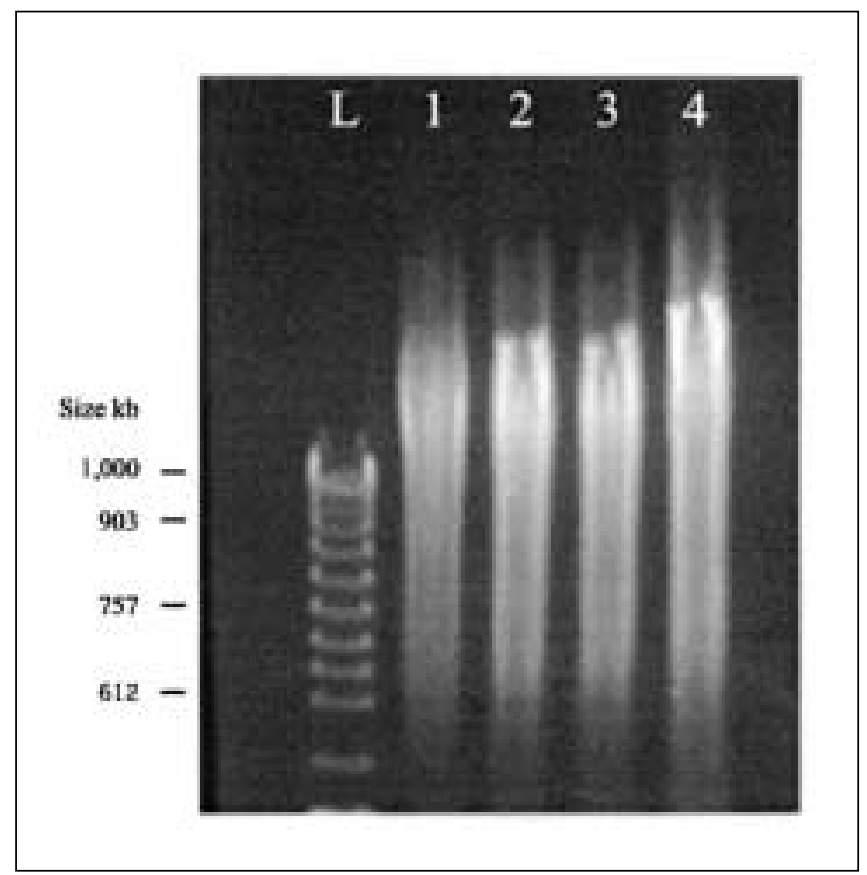

Figure 5. FIGE comparison. DNA was purified from two $10-\mathrm{mL}$ blood samples using the WBPS (lanes 1-2) or Camgen method (lanes 3-4). Five micrograms of DNA from each sample were loaded onto a gel containing $1 \%$ pulse field grade agarose. Samples were run under an inverse field for $14 \mathrm{~h}$, and the separated material was observed using ethidium bromide. The molecular weight size marker consisted of a $\lambda$ concatamer ladder (L). fresh blood, the WBPS method allows the purification of DNA from blood stored at $-20^{\circ} \mathrm{C}$ and $-80^{\circ} \mathrm{C}$. Furthermore, the use of anticoagulants other than EDTA (e.g., citrate) will not affect the purification process.

dsDNA purified from blood using WBPS can be used in a range of downstream applications including PCR, STR, and restriction digests. Furthermore, these investigations show that the purity and size of genomic DNA isolated using WBPS is at least equal to that purified using a salting-out method. In addition, the WBPS procedure enables the recovery of DNA from blood in a shorter time with the least amount technical expertise and user intervention. Given the simplicity and speed of this technology, it offers great potential for incorporation into an automated platform.

Preliminary experiments show that WBPS may be used for the purification of genomic DNA from biological samples other than blood. In particular, we have purified genomic DNA from samples that contain large nucleated cells, such as Jurkat and transformed lymphocyte cell lines, resulting in a recovery of up to $95 \%$ of the total theoretical yield in $10-\mathrm{mL}$ samples. This potential for recovering DNA from a wide range of biological samples combined with speed, purity, and high yield make WBPS a valuable tool for researchers.

\section{ACKNOWLEDGMENTS}

M.P.B. and A.M. contributed equally to this manuscript. Many thanks to Martin Smith for proof reading the manuscript.

\section{REFERENCES}

1.Akane, A., K. Matsubara, H. Nakamura, S. Takahashi, and K. Kimura. 1994. Identification of heme compound copurified with deoxyribonucleic acid (DNA) from bloodstains, a major inhibitor of polymerase chain reaction (PCR) amplification. J. Forensic Sci. 39:362-372.

2.Boom, R., C.J.A. Sol, M.M.M. Salimans, C.L. Jansen, P.M.E. Wertheim-van Dillen, and J. van der Noordaa. 1990. Rapid and simple method for purification of nucleic acids. J. Clin. Microbiol. 28:495-503.

3.Boom, R., C. Sol, M. Beld, J. Weel, J. Goudsmit, and P. Wertheim-van Dillen. 1999. Improved silica-guanidiniumthiocyanate DNA isolation procedure based on selective binding of bovine alpha-casein to selective silica particles. J. Clin. Microbiol. 37:615-619.

4.Buffone, G.J. 1985. Isolation of DNA from biological specimens without extraction with phenol. Clin. Chem. 31:164-165.

5.Johns, Jr., M.B. and J.E. Paulus-Thomas. 1989. Purification of human genomic DNA from whole blood using perchlorate in place of phenol. Anal. Biochem. 180:276-278.

6.Madisen, L., D.I. Hoar, C.D. Holroyd, M. Crisp, and M.E. Hodes. 1987. DNA banking: the effects of storage of blood and isolated DNA on the integrity of DNA. Am. J. Med. Genet. 27:379-390.

7.Miller, S.A., D.D. Dykes, and H.F. Polesky. 1988. A simple salting out procedure for extracting DNA from human nucleated cells. Nucleic Acids Res. 16:1215.

8.Vogelstein, B. and D. Gillespie. 1979. Preparative and analytical purification of DNA from agarose. Proc. Natl. Acad. Sci. USA 76:615.

Address correspondence to Dr. Neil Butt, Whatman BioScience, Granta Park, Abington, Cambridge CB1 6GR, UK. e-mail:nbutt@whatman.co.uk 